\title{
Prevention of postoperative bleeding after complex pediatric cardiac surgery by early administration of fibrinogen, prothrombin complex and platelets: a prospective observational study
}

Nils Dennhardt ${ }^{1 *}$ (D), Robert Sümpelmann ${ }^{1}$, Alexander Horke², Oliver Keil ${ }^{1}$, Katja Nickel ${ }^{1}$, Sebastian Heiderich ${ }^{1}$, Dietmar Boethig ${ }^{2+}$ and Christiane E. Beck ${ }^{1+}$

\begin{abstract}
Background: Postoperative bleeding is a major problem in children undergoing complex pediatric cardiac surgery. The primary aim of this prospective observational study was to evaluate the effect of an institutional approach consisting of early preventive fibrinogen, prothrombin complex and platelets administration on coagulation parameters and postoperative bleeding in children. The secondary aim was to study the rate of re-intervention and postoperative transfusion, the occurrence of thrombosis, length of mechanical ventilation, ICU stay and mortality.

Methods: In fifty children (age 0-6 years) with one or more predefined risk factors for bleeding after cardiopulmonary bypass (CPB), thrombelastography (TEG) and standard coagulation parameters were measured at baseline (T1), after CPB and reversal of heparin (T2), at sternal closure (T3) and after $12 \mathrm{~h}$ in the ICU (T4). Clinical bleeding was evaluated by the surgeon at T2 and T3 using a numeric rating scale (NRS, 0-10).

Results: After CPB and early administration of fibrinogen, prothrombin complex and platelets, the clinical bleeding evaluation score decreased from a mean value of $6.2 \pm 1.9$ (NRS) at T2 to a mean value of $2.1 \pm 0.8$ at T3 (NRS; $P<0.001)$. Reaction time $(R)$, kinetic time $(K)$, maximum amplitude $(M A)$ and maximum amplitude of fibrinogen (MA-fib) improved significantly $(P<0.001$ for all), and MA-fib correlated significantly with the clinical bleeding evaluation $(r=0.70, P<0.001)$. The administered total amount of fibrinogen $\left(\mathrm{mg} \mathrm{kg}^{-1}\right)$ correlated significantly with weight ( $r=-0.42, P=0.002)$, priming volume as percentage of estimated blood volume $(r=0.30, P=0.034)$, minimum CPB temperature $(r=-0.30, P=0.033)$ and the change in clinical bleeding evaluation from T2 to T3 $(r=0.71, P<0.001)$. The incidence of postoperative bleeding ( $>10 \%$ of estimated blood volume) was $8 \%$. No child required a surgical re-intervention, and no cases of thrombosis were observed. Hospital mortality was $0 \%$.

(Continued on next page)
\end{abstract}

\footnotetext{
* Correspondence: Dennhardt.Nils@mh-hannover.de

Dietmar Boethig and Christiane E. Beck share responsibility as last author.

${ }^{1}$ Clinic for Anaesthesiology and Intensive Care Medicine, Hannover Medical

School, OE 8050, Carl-Neuberg-Str. 1, D-30625 Hannover, Germany

Full list of author information is available at the end of the article
}

(C) The Author(s). 2020 Open Access This article is licensed under a Creative Commons Attribution 4.0 International License, which permits use, sharing, adaptation, distribution and reproduction in any medium or format, as long as you give appropriate credit to the original author(s) and the source, provide a link to the Creative Commons licence, and indicate if changes were made. The images or other third party material in this article are included in the article's Creative Commons licence, unless indicated otherwise in a credit line to the material. If material is not included in the article's Creative Commons licence and your intended use is not permitted by statutory regulation or exceeds the permitted use, you will need to obtain permission directly from the copyright holder. To view a copy of this licence, visit http://creativecommons.org/licenses/by/4.0/ The Creative Commons Public Domain Dedication waiver (http://creativecommons.org/publicdomain/zero/1.0/) applies to the data made available in this article, unless otherwise stated in a credit line to the data. 
(Continued from previous page)

Conclusion: In this observational study of children with an increased risk of bleeding after CPB, an early preventive therapy with fibrinogen, prothrombin complex and platelets guided by clinical bleeding evaluation and TEG reduced bleeding and improved TEG and standard coagulation parameters significantly, with no occurrence of thrombosis or need for re-operation.

Trial registration: German Clinical Trials Register DRKS00018109 (retrospectively registered 27th August 2019).

Keywords: Children, Bleeding, Cardiopulmonary bypass, Fibrinogen, Thrombelastography

\section{Background}

Postoperative bleeding is a major problem in children with congenital heart disease undergoing complex pediatric cardiac surgery with cardiopulmonary bypass $(\mathrm{CPB})$ and results in significant postoperative morbidity and mortality $[1,2]$. Risk factors associated with a higher incidence of bleeding are an age of less than 1 year, hypothermia on $\mathrm{CPB}$, longer $\mathrm{CBP}$ duration and resternotomy [3]. For the prevention of massive bleeding, blood products and coagulation factor concentrates can be used early after CPB $[4,5]$. In our institution, fibrinogen, prothrombin complex concentrate and platelets are used routinely in children with an increased bleeding risk until sufficient hemostasis is achieved and surgical closure of the thorax is possible. More than ten years of experience have shown this approach to be safe and effective, but no objective evaluation has been performed yet. Therefore, we conducted a prospective clinical observational study to investigate the impact of our institutional approach on children with increased risk of postoperative bleeding. The primary aim was to evaluate the effect on standard coagulation parameters, thrombelastography and postoperative bleeding. The secondary aim was to study the rate of re-intervention and postoperative transfusion, the occurrence of thrombosis, length of mechanical ventilation, ICU stay and mortality.

\section{Methods}

\section{Patients}

This prospective observational study was conducted according to the standards set forth by the Declaration of Helsinki and Good Clinical Practice guidelines. Following the local ethics committee's approval (Ethics Committee of Hanover Medical School, Germany, Chairperson Prof. Dr. H. D. Troeger, No. 7349 dated February 2, 2017), 50 children ranging from 0 to 6 years of age scheduled for cardiac surgery with $\mathrm{CPB}$ and one or more risk factors for bleeding were included (Fig. 1). The risk factors were predefined as an age of less than 1 year, hypothermia on $\mathrm{CPB}<32{ }^{\circ} \mathrm{C}$, expected $\mathrm{CPB}$ duration $>90 \mathrm{~min}$, re-sternotomy or extensive aortic suture lines. Children with pre-existing coagulation disorders or on anticoagulant or antiplatelet therapy were excluded. The study was conducted from April 2017 to November
2018 at the Clinic for Anesthesiology and Intensive Care Medicine, Hanover Medical School, Germany, and all operations were performed by the same team of surgeons.

\section{Intraoperative management}

Anesthesia was induced by injection of $0.5 \mathrm{mg} \mathrm{kg}^{-1}$ etomidate, $0.5 \mu \mathrm{g} \mathrm{kg}^{-1}$ sufentanil and $0.5 \mathrm{mg} \mathrm{kg}^{-1}$ atracurium and maintained by sufentanil $1 \mu \mathrm{g} \mathrm{kg}^{-1} \mathrm{~h}^{-1}$ and sevoflurane (on $\mathrm{CPB}$ administered via oxygenator).

$\mathrm{CPB}$ was performed with the heart-lung machine LivaNova S5 (LivaNova PLC, London, UK) and the oxygenator system TerumoFX05 (Terumo Corporation, Tokyo, Japan). The system was prepared in a standardized fashion: The circuit was primed with a bicarbonate-buffered hemofiltration solution (BB-HS; Duosol, B. Braun, Melsungen, Germany), $2 \mathrm{~mL} \mathrm{~kg}^{-1}$ mannitol, $150 \mathrm{IU} \mathrm{kg}^{-1}$ of heparin and $20 \mathrm{~mL} \mathrm{~kg}^{-1}$ gelatin. In infants with a body weight below $5 \mathrm{~kg}, 10 \mathrm{~mL} \mathrm{~kg}^{-1}$ albumin $20 \%$ was used instead of gelatin. Packed red blood cells were added if necessary to achieve hemoglobin levels of $8-10 \mathrm{~g} \mathrm{dL}^{-1}$. According to patient's weight, the total priming volume fluctuated between 180 and $450 \mathrm{ml}$. To achieve a physiological composition, priming volume was hemofiltered before $\mathrm{CPB}$ using a polysulfone hemofilter (ME HFOS 0020, Medos AG, Stolberg, Germany) by ten minutes circulation until approximately $1000 \mathrm{~mL}$ of ultrafiltrate were restored by BB-HS [6]. During the last $30 \mathrm{~min}$ of $\mathrm{CPB}, 20-30 \mathrm{~mL} \mathrm{~kg}^{-1}$ fresh frozen plasma was added, and a higher amount of fluid was removed by hemofiltration. Target pump flow was $2.7 \mathrm{~L} \mathrm{~min}^{-1} \mathrm{~m}^{-2}$ for children and $3.0 \mathrm{~L} \mathrm{~min}^{-1} \mathrm{~m}^{-2}$ for infants below one year of age. Target mean arterial pressure was guided by nearinfrared spectroscopy (NIRS) and continuously measured central venous oxygen saturation in the venous line of the bypass. Before CPB, a heparin bolus of 400 $\mathrm{IU} \mathrm{kg}{ }^{-1}$ was given to achieve anticoagulation. During $\mathrm{CPB}$, activated clotting time (ACT) was maintained longer than $400 \mathrm{~s}$ by adding additional heparin if necessary. Tranexamic acid was administered at $10 \mathrm{mg} \mathrm{kg}^{-1} \mathrm{~h}^{-1}$. At the end of $\mathrm{CPB}$, the administered heparin was reversed by protamine starting at a ratio of 0.8 until the ACT had returned to $<130 \mathrm{~s}$. 
Children $\leq 6 \mathrm{y}$ with $\mathrm{CHD}$

scheduled for cardiac surgery $\mathrm{n}=375$

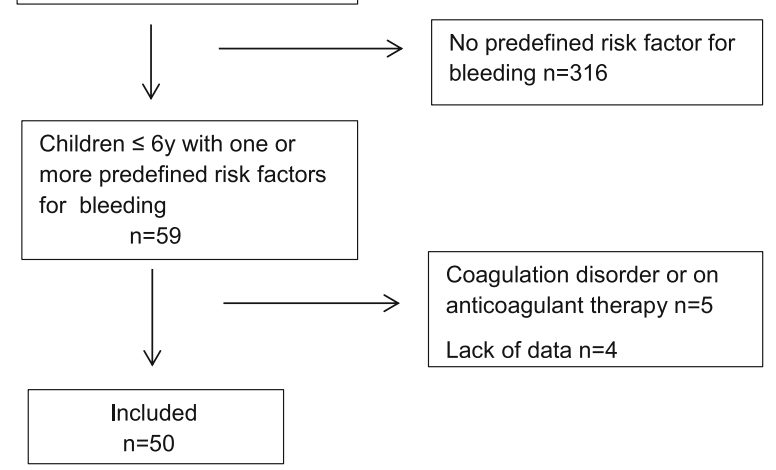

Fig. 1 Study flow chart

After CPB weaning, heparin reversal and clinical bleeding evaluation, the hemostatic therapy was started with $50 \mathrm{mg} \mathrm{kg}^{-1}$ human fibrinogen (Haemocomplettan', CSL Behring GmbH, Marburg, Germany), $50 \mathrm{IU} \mathrm{kg}^{-1}$ human prothrombin complex (Beriplex ${ }^{\oplus}$, CSL Behring $\mathrm{GmbH}$, Marburg, Germany) and $20 \mathrm{~mL} \mathrm{~kg}^{-1}$ platelets. Repeat doses were guided by clinical bleeding evaluation and TEG as follows: In case of MA-fib $<15 \mathrm{~mm}$, fibrinogen was added; in case of $\mathrm{R}>9.5 \mathrm{~min}$, prothrombin complex was added; and in case of MA $<52 \mathrm{~mm}$ and normal MA-fib (>15 mm), platelets were added until the bleeding situation improved clinically significant and closure of the thorax was possible.

\section{Data collection}

Results of blood gas analysis, hematologic (hemoglobin, hematocrit, platelets), coagulation standard (Quick value of prothrombin time (Quick), activated partial thromboplastin time (aPTT), activated clotting time (ACT), fibrinogen (Clauss method), antithrombin III, factor II, factor V and TEG parameters (reaction time (R), kinetic time (K), angle, maximum amplitude (MA), functional fibrinogen, maximum amplitude of functional fibrinogen (MA-fib), fibrinolysis at $30 \mathrm{~min}$ after maximum amplitude (LY30)) were collected at the following points in time: at baseline before skin incision (T1); after CPB and reversal of heparin by protamine before administration of coagulation factors or blood products (T2); at sternal closure (T3); and after $12 \mathrm{~h}$ in the ICU (T4). For the TEG analysis, the TEG $6 \mathrm{~s}$ analyzer (Haemonetics, Braintree, Massachusetts, USA) was used. At T2 and T3, the operating surgeon was asked to evaluate the bleeding on a numeric rating scale from 0 to 10 (NRS; $0=$ absolutely dry, no signs of any bleeding at all; $10=$ massive bleeding with no signs of coagulation). The administered coagulation factors and blood products were documented. Intraoperative data included $\mathrm{CPB}$ time, cross-clamp time, duration of deep hypothermic circulatory arrest (if used) and the lowest temperature during $\mathrm{CPB}$. Postoperative data included chest drainage output within the first six postoperative hours, rate of re-intervention and postoperative transfusion, the occurrence of thrombosis, length of mechanical ventilation, ICU stay and mortality. Significant postoperative bleeding was defined as a blood loss of more than $10 \%$ of the child's estimated blood volume within the first six postoperative hours.

\section{Statistics}

Data were recorded in an Excel database, analyzed using MS Excel (Excel 2010; Microsoft, Seattle, USA) and GraphPad Prism (Prism 7; Graph Pad Software Inc., San Diego, USA) software tools, and presented as mean values plus standard deviation (range) or as median (range). Spearman correlation, regression analysis and independent-samples Mann-Whitney-U tests were performed with a pre-defined significance level of $\alpha=0.05$.

\section{Results}

A total of 50 children were included. Surgical procedures are summarized in Table 1. Demographic, intra- and postoperative data are summarized in Table 2.

Besides hemoglobin concentration, there were no significant differences between cyanotic and non-cyanotic children in measured hematologic, coagulation standard or TEG parameters at baseline (T1). After CPB and administration of protamine (T2), hemoglobin, hematocrit, platelets, Quick, fibrinogen, AT III, factor II, angle, MA,

Table 1 Surgical procedure type $(n=50)$

\begin{tabular}{ll}
\hline Procedures & $\mathbf{n}$ \\
\hline TOF repair & 7 \\
AA repair & 6 \\
ASO & 5 \\
Fontan & 5 \\
ASO + AA repair & 3 \\
TAC repair & 3 \\
TE-AV replacement & 3 \\
bilateral Glenn & 3 \\
ASO + VSD repair & 2 \\
TAPVC repair & 2 \\
CAVC repair & 2 \\
AV repair & 2 \\
AA repair + VSD repair & 1 \\
Rastelli & 1 \\
Other & 5
\end{tabular}

Abbreviations: TOF tetralogy of Fallot, $A A$ aortic arch, $A S O$ arterial switch operation, VSD ventricular septal defect, TAC truncus arteriosus communis, TE$A V$ tissue-engineered aortic valve, TAPVC total anomalous pulmonal vein connection, CAVC complete atrio-ventricular channel, $A V$ aortic valve 
Table 2 Demographic, intra-, and postoperative data $(n=50)$ Data are presented as mean \pm standard deviation (range) or number (percentage)

\begin{tabular}{|c|c|}
\hline Age (months) & $15.6 \pm 22.5(0-74)$ \\
\hline Weight (kg) & $8.1 \pm 5.9(2.0-24.2)$ \\
\hline Height (cm) & $70.1 \pm 21.2(47-118)$ \\
\hline Cyanotic (n) & $32(64 \%)$ \\
\hline Neonate (n) & $12(24 \%)$ \\
\hline Re-operation (n) & $19(38 \%)$ \\
\hline Hypothermia $<32^{\circ} \mathrm{C}$ (n) & $42(84 \%)$ \\
\hline Priming Volume (\% of EBV) & $57 \pm 24(25-112)$ \\
\hline Lowest temp. $\left({ }^{\circ} \mathrm{C}\right)$ & $24.9 \pm 4.8(17.9-34.0)$ \\
\hline CPB time (min) & $231 \pm 84(91-492)$ \\
\hline Cross-clamp time (min) & $127 \pm 62(28-256)$ \\
\hline DHCA (min) & $24 \pm 6(8-32)(n=11)$ \\
\hline Drainage volume within $6 \mathrm{~h}$ (\% of EBV) & $6.7 \pm 3.7(2.3-20.2)$ \\
\hline Drainage volume within $6 h>10 \%$ of EBV $(n)$ & $4(8 \%)$ \\
\hline Surgical re-intervention (n) & 0 \\
\hline Thrombosis (n) & 0 \\
\hline Mechanical ventilation duration (h) & $39 \pm 51(2-255)$ \\
\hline ICU stay (days) & $5.0 \pm 3.9(1-19)$ \\
\hline Mortality (\%) & 0 \\
\hline
\end{tabular}

Abbreviations: $E B V$ estimated blood volume, $C P B$ cardiopulmonary bypass, $D H C A$ deep hypothermic circulatory arrest, $I C U$ intensive care unit

MA-fib and LY30 were significantly reduced, and R and $\mathrm{K}$ were significantly extended, as compared to the baseline values (T1) $(P<0.001$ for all). ACT, aPTT and factor $\mathrm{V}$ did not differ significantly (Table 3). At this point in time (T2), the surgeon evaluated clinical bleeding at a mean value of $6.2 \pm 1.9$ on a numeric rating scale, and the administration of fibrinogen (mean total amount $108 \pm 56 \mathrm{mg} \mathrm{kg}^{-1}$ ), prothrombin complex concentrate (mean total amount $70 \pm 26 \mathrm{IU} \mathrm{kg}^{-1}$ ), platelets (mean total amount $22 \pm 14 \mathrm{~mL} \mathrm{~kg}^{-1}$ ) and red blood cells (mean total amount $18.9 \pm 18 \mathrm{~mL} \mathrm{~kg}^{-1}$ ) was started. In combination with surgical hemostasis, the results of the clinical bleeding evaluation score reduced significantly to a mean of $2.1 \pm 0.8(P<0.001)$. At sternal closure (T3), platelets, Quick, fibrinogen, factor II, angle, MA and MA-fib had significantly increased, and $\mathrm{R}$ and $\mathrm{K}$ had significantly decreased $(P<0.001$ for all, Table 3$)$.

Results of TEG parameters and clinical bleeding evaluation are shown in Fig. 2. MA-fib correlated significantly with the clinical bleeding evaluation $(r=0.70$, $P<0.001)$. The administered total amount of fibrinogen $\left(\mathrm{mg} \mathrm{kg}^{-1}\right)$ correlated significantly with age $(r=-0.41$, $P=0.003)$, weight $(r=-0.42, P=0.002)$, priming volume as percentage of estimated blood volume $(r=0.30$, $P=0.034)$, minimum CPB temperature $(r=-0.30, P=$ 0.033 ) and the change in clinical bleeding evaluation from T2 to T3 $(r=0.71, P<0.001$; Fig. 3$)$. Patients weighing less than $8 \mathrm{~kg}$ had significantly higher scores in clinical bleeding evaluation after CPB $(P=0.039)$ and received significantly higher fibrinogen doses thereafter $\left(\mathrm{mg} \mathrm{kg}^{-1}, \quad P=0.002\right)$. The plasma fibrinogen levels (Clauss method) correlated significantly with functional fibrinogen $(r=0.76)$ and MA-fib $(r=0.75, P<0.0001$ for both). The results of systemic perfusion after CPB evaluated by arteriovenous oxygen saturation difference (mean $26.8 \pm 8.9$ ) were adequate in all cases.

In the ICU (T4), hematologic, coagulation standard and TEG parameters after $12 \mathrm{~h}$ remained stable. The mean chest drainage volume within the first six postoperative hours was $5.3 \pm 2.9(1.8-16.1) \mathrm{mLkg}^{-1}$; this is equivalent to $6.7 \pm 3.7(2.3-20.2) \%$ loss of EBV. Four children (8\%) had a postoperative blood loss of $>10 \%$ of EBV. Nine children (18\%) received further red blood cell transfusions (mean $11.4 \pm 2.4,8-16 \mathrm{~mL} \mathrm{~kg}^{-1}$ ) and one child $50 \mathrm{mg} \mathrm{kg}^{-1}$ fibrinogen. Length of mechanical ventilation was $39 \pm 51(2-255)$ hours, and the mean ICU stay was $5.0 \pm 3.9$ (1-19) days. No child needed surgical reintervention, no case of thrombosis was observed, and overall mortality was $0 \%$.

\section{Discussion}

Our study showed that nearly all children with risk factors for bleeding presented with significant coagulation disorders after $\mathrm{CPB}$, that an early preventive therapy with fibrinogen, prothrombin complex concentrate and platelets improved the hemostasis with no occurrence of thrombosis or need for re-operation and that a low body weight and a low CPB temperature were associated with higher administered fibrinogen doses $\left(\mathrm{mg} \mathrm{kg}^{-1}\right)$.

Excessive bleeding after cardiopulmonary bypass is a serious complication and may be caused by coagulopathy and insufficient surgical hemostasis. Contributory mechanisms include heparinization and hemodilution through the circuit prime, exposure of blood to artificial surfaces, hypothermia and interactions between the inflammatory and coagulation systems [7]. Maintenance of a stable homeostasis is of high importance and therefore bicarbonate- buffered ultrafiltration was favored to achieve a physiologic priming solution and to prevent electrolyte and acid- base disturbances $[6,8]$. Fresh frozen plasma (FFP) was added during rewarming and ultrafiltration on CPB to avoid fluid overload, but the results of clinical bleeding evaluation, TEG and standard coagulation parameters at T2 showed that FFP alone was not effective to prevent bleeding. Therefore, coagulation factor concentrates and platelets were added subsequently, and this strategy improved the results of clinical bleeding evaluation and thrombelastography significantly. 
Table 3 Hematologic, coagulation standard and TEG parameters, and clinical bleeding as assessed by surgeon at baseline (T1), after bypass and administration of protamine (T2), at sternal closure (T3), and in ICU after $12 \mathrm{~h}$ (T4). Data are presented as median (range)

\begin{tabular}{|c|c|c|c|c|c|c|c|c|}
\hline & T1 & $\mathrm{T} 2$ & T3 & $\mathrm{T} 4$ & $\begin{array}{l}P \text { (T1 vs } \\
\text { T2) }\end{array}$ & $\begin{array}{l}95 \%-\mathrm{Cl} \text { for } P \\
\text { (T1 vs T2) }\end{array}$ & $\begin{array}{l}P \text { (T2 vs } \\
\text { T3) }\end{array}$ & $\begin{array}{l}95 \%-\mathrm{Cl} \text { for } \\
P(\text { T2 vs T3) }\end{array}$ \\
\hline $\mathrm{Hb}\left(\mathrm{g} \mathrm{dl}^{-1}\right)$ & $13.4(8.2-18.4)$ & $11.4(8.5-15.8)$ & $12.2(9.3-16.9)$ & $13.7(9.5-17.8)$ & $<0.001$ & 1.4 to 3.1 & ns & \\
\hline Hct (\%) & $40.6(25.2-55.1)$ & $34.9(24.1-48.5)$ & $36.7(28.5-49.0)$ & $38.1(26.9-52.5)$ & $<0.001$ & -23.7 to 0.51 & ns & \\
\hline $\operatorname{PLT}\left(10^{9} \mathrm{~L}^{-1}\right)$ & $279(155-621)$ & $116(68-266)$ & 219 (112-329) & $246(123-380)$ & $<0.001$ & -233 to -169.5 & $<0.001$ & 83.9 to 121. \\
\hline Quick (\%) & $92(54-129)$ & $49(40-82)$ & $85(62-130)$ & $83(59-130)$ & $<0.001$ & -44.1 to -33.8 & $<0.001$ & 28.6 to 37.9 \\
\hline aPTा (s) & $32(23-50)$ & $41(31-55)$ & $38(26-59)$ & $31(24-49)$ & ns & & ns & \\
\hline$A C T(s)$ & $110(91-148)$ & $114(91-146)$ & 106 (79-138) & 110 (89-126) & ns & & ns & \\
\hline Fib $\left(\mathrm{g} \mathrm{L}^{-1}\right)$ & $1.7(0.9-3.3)$ & $1.4(0.3-2.2)$ & $2.2(1.5-3.5)$ & $2.5(1.3-3.8)$ & $<0.001$ & -0.49 to -0.14 & $<0.001$ & 0.6 to 1.0 \\
\hline AT III (\%) & $89(44-120)$ & 67 (47-97) & $67(47-91)$ & $76(46-101)$ & $<0.001$ & -28.1 to -14.3 & ns & \\
\hline F II (\%) & 60 (32-94) & $49(34-87)$ & $113(70-170)$ & $101(62-167)$ & 0.04 & -12.5 to -1.5 & $<0.001$ & 56.3 to 72.2 \\
\hline FV (\%) & $77(57-121)$ & $61(37-81)$ & $60(32-89)$ & $72(33-148)$ & ns & & ns & \\
\hline$R(\min )$ & $6.9(4.3-10.7)$ & $10.0(5.7-15.3)$ & $7.9(5.2-12.1)$ & $7.2(3.5-11.2)$ & $<0.001$ & 1.9 to 3.1 & $<0.001$ & -2.2 to -0.6 \\
\hline$K(\min )$ & $1.5(0.9-4.3)$ & $2.8(0.9-7.4)$ & $1.8(1.0-3.7)$ & $1.2(0.7-2.1)$ & $<0.001$ & 0.7 to 1.5 & $<0.001$ & -1.4 to -0.6 \\
\hline Angle (degree) & $70.7(48.4-77.8)$ & $59.1(38.0-77.4)$ & $68.9(56.9-77.8)$ & $74.4(63.9-81.7)$ & $<0.001$ & -11.7 to -5.9 & $<0.001$ & 5.9 to 11.3 \\
\hline $\mathrm{MA}(\mathrm{mm})$ & $59.0(43.9-69.7)$ & $48.9(30.5-64.1)$ & $62.0(50.6-68.6)$ & $64.3(55-69.6)$ & $<0.001$ & -12.0 to -7.3 & $<0.001$ & 9.1 to 13.5 \\
\hline MA-fib (mm) & $19.6(11.1-35.5)$ & $13.2(4.9-21.0)$ & $29.1(19.5-53.2)$ & $32.0(23.0-50.6)$ & $<0.001$ & -9.5 to -6.1 & $<0.001$ & 15.5 to 19.9 \\
\hline LY30 (\%) & $0.6(0-5.1)$ & $0.0(0-3.2)$ & $0.0(0-3.8)$ & $0.6(0-2.7)$ & 0.008 & -1.1 to 0.2 & ns & \\
\hline Bleeding (NRS 0-10) & & $6(2-10)$ & $2(0-4)$ & & & & $<0.001$ & -4.8 to -3.6 \\
\hline
\end{tabular}

Prothrombin complex concentrates contain coagulation factors required to directly promote thrombin generation [5]. Studies including adults after CPB suggest that the use of prothrombin complex concentrate as part of a multimodal coagulation management strategy may have blood sparing effects $[9,10]$, but there is a lack of randomized controlled studies in both adult and pediatric patients. The main concern regarding the use of prothrombin complex concentrate is the possibility of thrombotic complications especially in children with a low cardiac output and artificial shunts [11]. Neither in our study or in our clinical practice have cases of thrombosis been observed, but the sample size was too low to assess safety. Therefore, the individual risk of thrombosis should be weighed against the perioperative risk of bleeding when using prothrombin complex concentrates in children undergoing complex pediatric cardiac surgery.

Fibrinogen is the major substrate for clot formation and additionally promotes platelet activation and agglomeration. Hemodilution from $\mathrm{CPB}$ results in decreased fibrinogen levels, which in turn results in impaired fibrin formation, inadequate clot formation and bleeding. Faraoni et al. [12] demonstrated in a retrospective analysis that the post-CPB plasma fibrinogen concentration significantly impacts blood loss in children undergoing cardiac surgery. Downey et al. [13] suggested that fibrinogen concentrate may be considered as an alternative to cryoprecipitate in infants with bleeding after $\mathrm{CPB}$, but cryoprecipitate is not available in Germany. Mahovec et al. demonstrated that measuring fibrinogen levels during the rewarming phase of $\mathrm{CPB}$ reduced cryoprecipitate transfusion [14]. An animal experimental study showed that hemotherapy with fibrinogen did not affect arterial thrombogenesis [15]. Guidelines by the European Society of Anesthesiology recommend to keep the level of plasma fibrinogen at no less than 1.5 to $2 \mathrm{~g} \mathrm{~L}^{-1}$ in bleeding patients [16]. In our study, most children had lower levels immediately after CPB but all had higher levels after fibrinogen administration at sternal closure. Therefore, keeping fibrinogen levels within a normal range should be one of the main goals to prevent bleeding in children undergoing complex cardiac surgery.

Platelet count and aggregation are markedly reduced after $\mathrm{CPB}$, especially in neonates, and patients with impaired platelet function during $\mathrm{CPB}$ had markedly increased intraoperative transfusion requirements $[17,18]$. Activation and aggregation of platelets following blood contact with foreign material, systemic inflammation, adverse effects of heparin on platelets and fibrinolytic system and hypothermia are among the most significant factors, but the relationship between postoperative bleeding and platelets dysfunction is a subject that is still 
a)

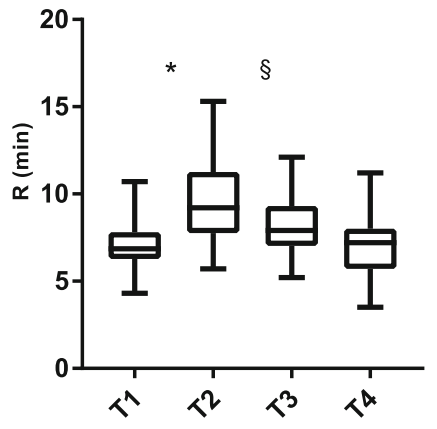

c)

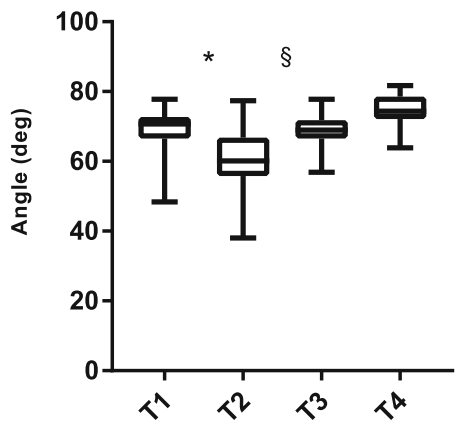

e)

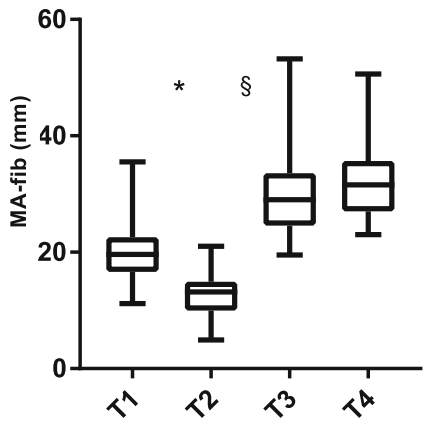

b)

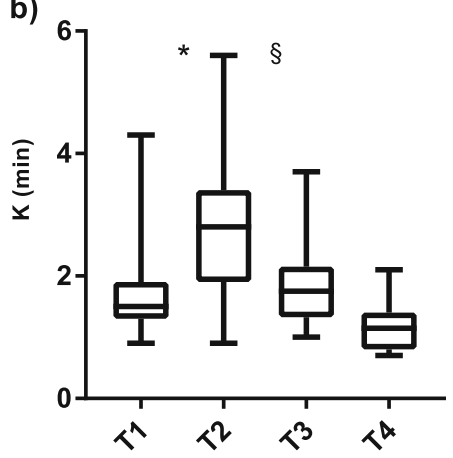

d)

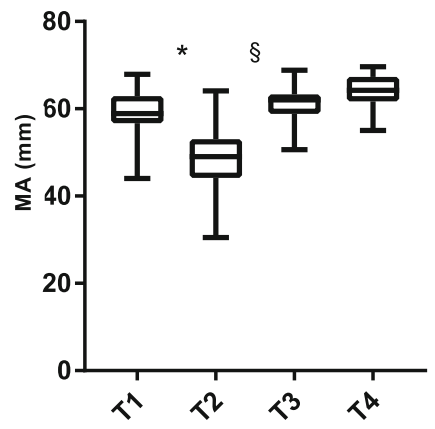

f)

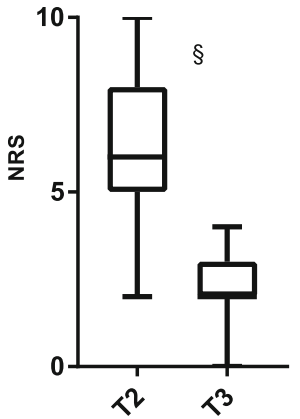

Fig. 2 Box and whisker plots (95th, 75th, 50th, and 5th percentiles) of TEG parameters (a-e) and clinical bleeding evaluated by surgeon (f) at baseline (T1), after bypass and administration of protamine (T2), at sternal closure (T3), and in ICU after 12 h (T4). Abbreviations: R, reaction time; K, kinetic time; MA, maximum amplitude; MA-fib, maximum amplitude of functional fibrinogen; NRS, numeric rating scale; * $P<0.001$ (T1 vs T2), $\S$ $P<0.001$ (T2 vs T3)

being debated [4]. In our study, platelet counts were decreased in many children after $\mathrm{CPB}$, but within a normal range after platelet transfusion at sternal closure. The platelet function was not analyzed, and therefore the hemostatic effect of the platelets transfused is unclear.

The TEG analyzer used in this study requires only a $300-\mu \mathrm{L}$ blood sample and processes the sample automatically without a time-consuming pipette procedure. The results of the functional fibrinogen measurements correlated with the Clauss method, which is in accordance with a previous study by Gautam et al. [19]. To avoid a time delay, the hemostatic therapy should be started early after CPB if diffuse bleeding is clinically evident. Thereafter, the results of TEG analysis can be used 
a)

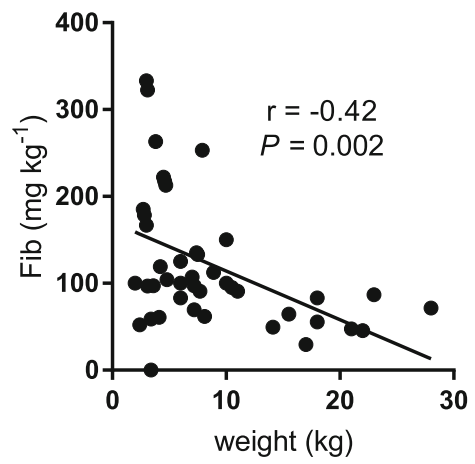

c)

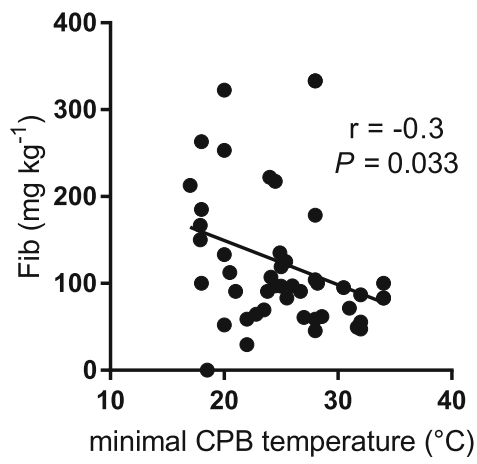

b)

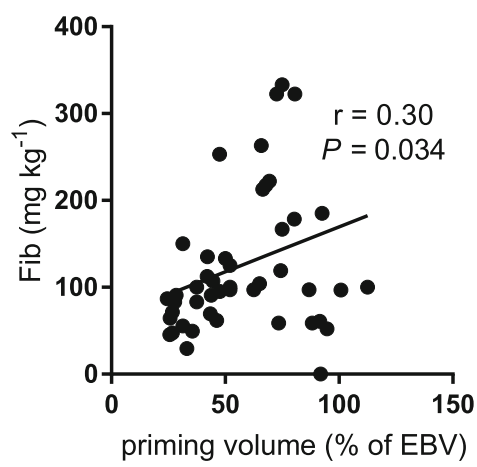

d)

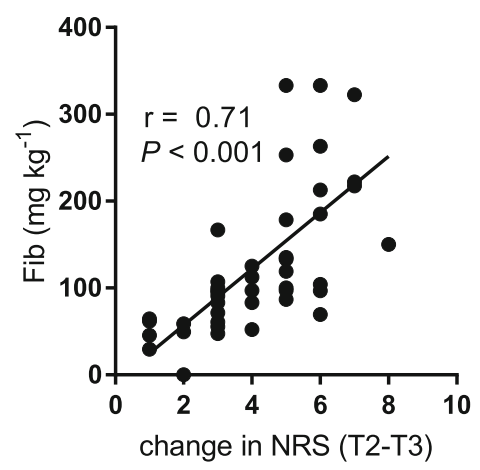

Fig. 3 Correlation between administered total amount of fibrinogen $\mathrm{kg}^{-1}$ and weight (a), priming volume as percentage of estimated blood volume weight (b), minimum temperature during cardiopulmonary bypass (c) and change in clinical bleeding evaluation from T2 to T3 (d). Abbreviations: Fib, fibrinogen; EBV, estimated blood volume; CPB, cardiopulmonary bypass; NRS, numeric rating scale

to guide the hemostatic therapy in more detail until a stable clot formation is achieved [20]. In cases with difficult bleeding localization, this strategy can help to identify areas with surgical bleeding. Besides the results of TEG analysis, a close cooperation with the attending surgeon is important to evaluate the bleeding situation and the efficacy of the administered hemostatic therapy. Therefore, careful clinical evaluation should be performed and TEG analysis should be repeated to control success and to adapt the hemostatic therapy, if necessary. Cui et al. demonstrated that the use of TEG in children undergoing complex cardiac surgery reduced perioperative transfusion and improved the outcome [21].

In our study, neonates and infants $<8 \mathrm{~kg}$ had significantly higher scores in clinical bleeding evaluation after $\mathrm{CPB}$ and needed significantly higher fibrinogen doses $\left(\mathrm{mg} \mathrm{kg}^{-1}\right)$ afterwards. These patients are at particular risk due to their immature coagulation systems and the mismatch between the $\mathrm{CPB}$ priming volume and the infants' blood volume [7]. Therefore, minimizing the priming volume and circuit should be an important goal, especially for small infants, and several studies reported safe use of miniaturized $\mathrm{CPB}$ circuits with a significant reduction of blood product transfusions [22-24]. While the benefits should be weighed against the downsides (e.g., reduced access to patient and circuit, vacuum assisted drainage - with the risk of air entrainment and hemolysis - often required, need for a very well-trained perfusion team), these techniques will probably be increasingly used in the future.

The incidence of clinically significant postoperative bleeding (8\%) defined as postoperative drainage volume $>10 \%$ of EBV within the first six postoperative hours was more than two times lower when compared to other studies (incidence $>20 \%$ ) $[25,26]$, even though these studies included also children without risk factors for bleeding. The major difference in hemostatic approach was the use of coagulation factors (fibrinogen, prothrombin complex concentrate) in the presented study. Also, other factors than hemostatic management alone may have contributed to the different results.

The presented study does, however, have some limitations. We performed a single-center prospective observational study on a special patient group (children below six years of age with one or more risk factors for bleeding) and the results may not be applicable to other populations. The attending anesthesiologists and surgeons 
were not blinded, and the sample size was too low to assess safety. The study design was observational and a randomization into groups of different fixed coagulation therapy regimens or a control group was not possible because of ethical reasons.

In conclusion, in this observational study of children with an increased risk of bleeding after complex cardiac surgery, an early preventive therapy with fibrinogen, prothrombin complex and platelets guided by clinical bleeding evaluation and thromboelastography (TEG) reduced bleeding and improved TEG and standard coagulation parameters significantly, with no occurrence of thrombosis or need for re-operation. Further studies are necessary to assess safety.

\section{Abbreviations}

CPB: Cardiopulmonary bypass; NRS: Numeric rating scale;

TEG: Thrombelastography; ACT: Activated clotting time; R: Reaction time; K: Kinetic time; MA: Maximum amplitude; MA-fib: Maximum amplitude of functional fibrinogen; LY30: Fibrinolysis at 30 min after maximum amplitude; ICU: Intensive care unit; FFP: Fresh frozen plasma; EBV: Estimated blood volume

\section{Acknowledgements}

The authors thank Matthaeus Vetter, Simone Hahn and Harald Koeditz for their assistance with perioperative data collection and Gideon Henner for professional language editing.

\section{Authors' contributions}

$\mathrm{ND}, \mathrm{RS}, \mathrm{AH}, \mathrm{OK}, \mathrm{KN}, \mathrm{SH}, \mathrm{DB}$ and CEB contributed to the study design, to collecting or analyzing data and drafting the manuscript. All authors have revised and approved the final version of the manuscript.

\section{Funding}

Personnel costs of this observational study were supported by CSL Behring $\mathrm{GmbH}$, Marburg, Germany. The funder did not influence the study design, and decisions about anesthetic management and the child's scheduled operation continued as per usual practice during data collection. Publication costs were supported by the German Research Foundation (DFG) and the Open Access Publication Fund of Hannover Medical School (MHH). Open Access funding enabled and organized by Projekt DEAL.

\section{Availability of data and materials}

The datasets used and/or analyzed during the study are available from the corresponding author on reasonable request.

\section{Ethics approval and consent to participate}

This observational study was approved by the local ethics committee (Ethics Committee of Hannover Medical School, Germany, Chairperson Prof. Dr. H. D. Troeger, No. 7349 dated February 2, 2017). The written consent of the parents or guardians was obtained via a treatment contract.

\section{Consent for publication}

Not applicable.

\section{Competing interests}

Nothing to declare.

\section{Author details}

${ }^{1}$ Clinic for Anaesthesiology and Intensive Care Medicine, Hannover Medical School, OE 8050, Carl-Neuberg-Str. 1, D-30625 Hannover, Germany. ${ }^{2}$ Clinic for Cardiac, Thoracic, Transplant and Vascular Surgery, Hannover Medical School, Carl-Neuberg-Str. 1, D-30625 Hannover, Germany.
Received: 20 April 2020 Accepted: 7 December 2020

Published online: 18 December 2020

\section{References}

1. Guzzetta NA, Allen NN, Wilson EC, et al. Excessive postoperative bleeding and outcomes in neonates undergoing cardiopulmonary bypass. Anesth Analg. 2015;120:405-10.

2. Wolf MJ, Maher KO, Kanter KR, et al. Early postoperative bleeding is independently associated with increased surgical mortality in infants after cardiopulmonary bypass. J Thorac Cardiovasc Surg. 2014;148:631-6 e1.

3. Williams GD, Bratton SL, Ramamoorthy C. Factors associated with blood loss and blood product transfusions: a multivariate analysis in children after open-heart surgery. Anesth Analg. 1999;89:57-64.

4. Durandy Y. Use of blood products in pediatric cardiac surgery. Artif Organs. 2015;39:21-7.

5. Guzzetta NA, Williams GD. Current use of factor concentrates in pediatric cardiac anesthesia. Paediatr Anaesth. 2017;27:678-87.

6. Osthaus WA, Sievers J, Breymann T, Suempelmann R. Bicarbonate buffered ultrafiltration leads to a physiologic priming solution in pediatric cardiac surgery. Interact Cardiovasc Thorac Surg. 2008;7:969-72.

7. Siemens K, Sangaran DP, Hunt BJ, et al. Strategies for prevention and Management of Bleeding Following Pediatric Cardiac Surgery on cardiopulmonary bypass: a scoping review. Pediatr Crit Care Med. 2018; 19:40-7.

8. Osthaus WA, Gorler H, Sievers J, et al. Bicarbonate-buffered ultrafiltration during pediatric cardiac surgery prevents electrolyte and acid-base balance disturbances. Perfusion. 2009;24:19-25.

9. Fitzgerald J, Lenihan M, Callum J, et al. Use of prothrombin complex concentrate for management of coagulopathy after cardiac surgery: a propensity score matched comparison to plasma. Br J Anaesth. 2018;120: 928-34

10. Ortmann E, Besser MW, Sharples LD, et al. An exploratory cohort study comparing prothrombin complex concentrate and fresh frozen plasma for the treatment of coagulopathy after complex cardiac surgery. Anesth Analg. 2015:121:26-33.

11. Ashikhmina E, Said S, Smith MM, et al. Prothrombin complex concentrates in pediatric cardiac surgery: the current state and the future. Ann Thorac Surg. 2017;104:1423-31.

12. Faraoni D, Willems A, Savan $V$, et al. Plasma fibrinogen concentration is correlated with postoperative blood loss in children undergoing cardiac surgery. A retrospective review. Eur J Anaesthesiol. 2014;31:317-26.

13. Downey LA, Andrews J, Hedlin $\mathrm{H}$, et al. Fibrinogen concentrate as an alternative to cryoprecipitate in a Postcardiopulmonary transfusion algorithm in infants undergoing cardiac surgery: a prospective randomized controlled trial. Anesth Analg. 2020;130:740-51.

14. Machovec KA, Smigla G, Ames WA, et al. Reduction in blood transfusion in a cohort of infants having cardiac surgery with cardiopulmonary bypass after instituting a goal-directed transfusion policy. Perfusion. 2016;31: 598-603.

15. Heinen A, Welke V, Behmenburg F, et al. Haemotherapy with fibrinogen for perioperative bleeding prevention-a view on arterial Thrombogenesis and myocardial infarction in the rat in vivo. J Clin Med. 2019;8:880.

16. Kozek-Langenecker SA, Ahmed AB, Afshari A, et al. Management of severe perioperative bleeding: guidelines from the European Society of Anaesthesiology: first update 2016. Eur J Anaesthesiol. 2017;34:332-95.

17. Romlin BS, Soderlund F, Wahlander $\mathrm{H}$, et al. Platelet count and function in paediatric cardiac surgery: a prospective observational study. Br J Anaesth. 2014;113:847-54.

18. Bonding Andreasen J, Hvas AM, Ravn HB. Marked changes in platelet count and function following pediatric congenital heart surgery. Paediatr Anaesth 2014:24:386-92.

19. Gautam NK, Cai C, Pawelek O, et al. Performance of functional fibrinogen thromboelastography in children undergoing congenital heart surgery. Paediatr Anaesth. 2017;27:181-9.

20. Nakayama Y, Nakajima Y, Tanaka KA, et al. Thromboelastometry-guided intraoperative haemostatic management reduces bleeding and red cell transfusion after paediatric cardiac surgery. Br J Anaesth. 2015;114:91-102.

21. Cui $Y$, Hei F, Long C, et al. Perioperative monitoring of thromboelastograph on blood protection and recovery for severely cyanotic patients undergoing complex cardiac surgery. Artif Organs. 2010;34:955-60. 
22. Bojan M, Constanza Basto Duarte M, Lopez Lopez V, et al. Use of a miniaturized cardiopulmonary bypass circuit in neonates and infants is associated with fewer blood product transfusions. ASAIO J. 2011;57:527-32.

23. Boettcher W, Dehmel F, Redlin M, et al. Complex cardiac surgery on patients with a body weight of less than $5 \mathrm{~kg}$ without donor blood transfusion. J Extra Corpor Technol. 2017:49:93-7.

24. Redlin M, Huebler M, Boettcher W, et al. Minimizing intraoperative hemodilution by use of a very low priming volume cardiopulmonary bypass in neonates with transposition of the great arteries. J Thorac Cardiovasc Surg. 2011;142:875-81.

25. Faraoni D, Willems A, Romlin BS, et al. Development of a specific algorithm to guide haemostatic therapy in children undergoing cardiac surgery: a single-Centre retrospective study. Eur J Anaesthesiol. 2015;32:320-9.

26. Savan V, Willems A, Faraoni D, Van der Linden P. Multivariate model for predicting postoperative blood loss in children undergoing cardiac surgery: a preliminary study. Br J Anaesth. 2014;112:708-14.

\section{Publisher's Note}

Springer Nature remains neutral with regard to jurisdictional claims in published maps and institutional affiliations.

Ready to submit your research? Choose BMC and benefit from:

- fast, convenient online submission

- thorough peer review by experienced researchers in your field

- rapid publication on acceptance

- support for research data, including large and complex data types

- gold Open Access which fosters wider collaboration and increased citations

- maximum visibility for your research: over $100 \mathrm{M}$ website views per year

At BMC, research is always in progress.

Learn more biomedcentral.com/submissions 